\title{
Data resource profile: Norwegian Databases for Drug Utilization and Pharmacoepidemiology
}

\author{
Hilchen Thode Sommerschild ${ }^{1}$, Christian Lie Berg ${ }^{1}$, Christian Jonasson², \\ Kari Jansdotter Husab $\varnothing^{3}$ and Mohammad Nouri Sharikabad ${ }^{1}$ \\ 1) Department of Drug Statistics, Health data and digitalization, Norwegian Institute of Public Health \\ 2) Health data and digitalization, Norwegian Institute of Public Health \\ 3) Department of Health Registries, Health data and digitalization, Norwegian Institute of Public Health \\ Correspondence: Mohammad Nouri Sharikabad, Department of Drug Statistics, Health Data and Digitalization, Norwegian Institute of Public Health \\ e-mail: mohammad.nouri.sharikabad@fhi.no
}

\begin{abstract}
In this article we aim to give researchers and other users of drug utilization data a current overview of the two nationwide Norwegian drug databases located at the Norwegian Institute of Public Health (NIPH), with reference to some historical background. The first database, "The Norwegian Drug Wholesales Statistics", dating back to 1974, provides total sale figures of all medicines on the market. The second database, "The Norwegian Prescription Database" (NorPD), dates back to 2004 and covers prescription drugs dispensed by pharmacies. This database will be modernized during 2021 and renamed ("The Norwegian Prescribed Drug Registry", name not finally decided), and all historical data will be migrated to the modernized registry. In the future, the most valuable add-on to the modernized prescription database will be individual level data from in-patients in hospitals and health care institutions, and the possibility to obtain aggregated data from each institution. Together, the two nationwide databases will continue to be the cornerstones of drug utilization data in Norway and should be used more extensively to improve health to the best for individuals and society. Development in national e-health programs will play a key role in providing easier and less time-consuming access to data and improve conditions for linkage of drug data to other health registries in the near future.
\end{abstract}

This is an open access article distributed under the Creative Commons Attribution Licence, which permits unrestricted use, distribution, and reproduction in any medium, provided the original work is properly cited.

\section{INTRODUCTION}

Drugs represent an important intervention in the prevention and care of many diseases, and more than $70 \%$ of Norwegians have at least one prescription drug dispensed annually. The drug market is expanding, as new therapeutic strategies and new drugs are continuously being developed. A growing number of drugs in the emerging field of "precision medicine", including advanced therapy medicinal products that targets smaller populations, are introduced in the hospital setting. Progress in digitalization and automation will improve data handling (speed, amount and quality) and provide new possibilities to systematically collect, link and report data. In this context, there is an increasing need for using population-based drug databases to monitor drug utilization in order to provide evidence-based information, valuable in a wide range of areas. Datadriven research and development as well as decisionmaking becomes increasingly important for health care professionals, health authorities and drug developers. For medical professionals it is important to ensure rational drug use in patients/individuals that balances benefit with risk. In a societal perspective, increasing drug use and consequently also costs, requires assessment of cost-effectiveness and effects on the overall public health.

\section{SHORT HISTORY OF DRUG UTILIZATION RESEARCH AND THE ATC/DDD CLASSIFICATION SYSTEM}

The history of development of drug utilization research reaches back to the 1960s (1-3). Drug utilization studies and pharmacoepidemiology have been developed alongside the society's need for more knowledge about medical, social and economic aspects of drug use. In 1961 the thalidomide tragedy was declared $(4,5)$. This was one of the first drug related crises, which became a major driving force for the development of the new science fields of drug utilization and pharmacoepidemiology. The development of the concepts of therapeutic formularies and essential drugs lists also significantly stimulated the development of drug utilization (2).

The Anatomical Therapeutic Chemical (ATC) classification system with a unit of measurement, the defined daily dose (DDD), was developed by the Norwegian Medicinal Depot (NMD) in cooperation with European scientists in the early 1970s. ATC was derived from the Anatomical Classification of Pharmaceutical Products by the European Pharmaceutical Market Research Association (EPhMRA). The ATC system developed one further level of classification, to allow for the complete chemical or pharmacolo- 


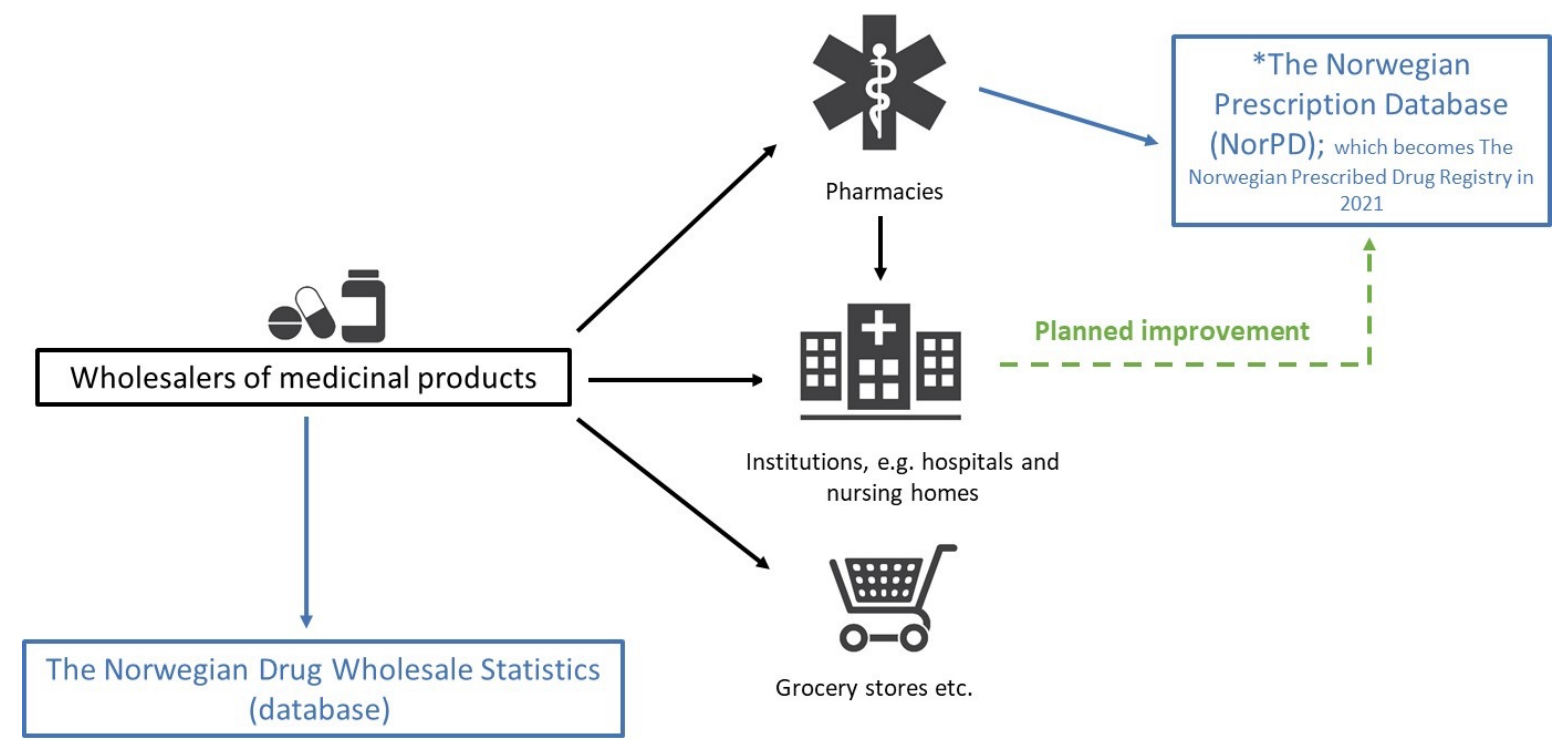

Figure 1. Illustration of the drug distribution (black) and data flow (blue) in Norway. Blue shows how drug sales are registered in two national databases, the Norwegian Drug Wholesales statistics and The Norwegian Prescription Database (NorPD). The green arrow and text indicate plans to capture individual-level data on patients directly from the digital drug handling systems in the health care institutions to the Norwegian Prescribed Drug Registry. Illustrasjon: Colourbox.com.

gical identification of each substance (6). Norway and the Nordic countries played a central role as pioneer countries in the creation of the ATC/DDD system which, in addition to the unique national identity number used in the Nordic countries, provided necessary methodological tools for drug utilisation research and pharmacoepidemiology $(1,7)$.

The "Nordic Council on Medicines" decided to publish "Nordic Statistics on Medicines" using the ATC/DDD methodology in 1976. The WHO Collaborating Centre for Drug Statistics Methodology was first established at NMD as the WHO Regional Office for Europe in 1982. The Centre was recognized as a global WHO Collaborating Centre in 1996. The ATC/DDD classification system is by now the WHO "gold standard" for classification of drugs. It is implemented in regulatory systems in Europe, Canada and Australia and several Asian and Latin American countries. In addition, it is used in databases for drug utilization research purposes in USA and other countries. This is making the ATC/DDD system an essential tool in the field of drug utilization and in pharmacoepidemiological research.

The Norwegian Drug Wholesales Statistics was established in 1974 at the NMD. This database has been the source of annual reports on aggregated drug sale since 1977. NMD had wholesale monopoly for drugs until 1995. The Norwegian Drug Wholesales Statistics has provided a significant contribution to national drug consumption statistics since then and has contributed to European and global statistics as well, e.g. comparative OECD statistics (8). Another milestone was reached by the establishment of The Norwegian Prescription Database (NorPD) in 2004 at the Norwegian Institute of Public Health (NIPH) (9) which includes data on pre- scribed drugs on individual basis dispensed at pharmacies. Since 2002, the WHO Collaborating Centre for Drug Statistics Methodology and the Norwegian Drug Wholesales Statistics have been under responsibility of and located at the NIPH. The proximity of the two Norwegian drug databases and the WHO Collaborating Centre for Drug Statistics Methodology at the NIPH has provided useful synergies and been important in building the necessary competence in drug classification and its practical use in drug utilization.

\section{TWO NATIONWIDE NORWEGIAN DRUG DATABASES}

Figure 1 illustrates drug distribution and data flow in Norway. Included are drugs with or without marketing authorization and pharmacy goods, not included are dietary supplements and herbal remedies. The Norwegian Prescription Database (NorPD) is currently under modernisation to "Legemiddelregisteret", the Norwegian Prescribed Drug Registry, (the new English name not finally decided). A unique identifier for each health institution is also under planning which allows collection of aggregated data from all institutions, either directly from health institutions or from pharmacies (or in some cases from wholesalers) supplying the institutions. The two databases are further described in the sections below.

\section{The Norwegian Drug Wholesales Statistics}

The Norwegian Drug Wholesales Statistics contains data from all wholesalers selling drugs (and pharmacy goods) to retailers, i.e. pharmacies, health institutions (e.g. hospitals and nursing homes), grocery retailers and others with permission to sell drugs. The database is 
organized according to the ATC/DDD classification system, but data are not person identifiable, key variables included are shown in table 1 . Wholesale activities with pharmaceuticals are regulated by law which is currently under revision ("Forskrift om grossistvirksomhet med legemidler") (10). At present, data from the Norwegian Drug Wholesales database is only available through our annual report (11), but researchers can gain access for defined projects by applying to NIPH.

\section{The Norwegian Prescription Database}

The Norwegian Prescription Database (NorPD) has information on all drugs dispensed by prescription in Norwegian pharmacies since 2004. The registry has information about the patient, the prescriber, the pharmacy and the dispensed drug. The purpose of the registry is to give information about use of drugs in Norway, for instance to facilitate research on the positive and negative effects of drug use. It is possible to link data from the NorPD with other Norwegian data sources.

In 2021, the NorPD will be modernized and renamed to the Norwegian Prescribed Drug Registry (the English name is not official yet, the Norwegian name is "Legemiddelregisteret"), which will include all historical data from 2004. This modernization will improve the technical infrastructure of the database and implement modern methods in compliance with the EU General Data Protection Regulation (GDPR). In contrast to the former and pseudonymous Norwegian Prescription Database, the individuals will be identified by their Norwegian national identity number in the Norwegian Prescribed Registry, in accordance with the recently revised Health Register Act (12). Person-identifiable data will make it easier and less time consuming to access data for research purposes and provide better conditions for registry linkages and studies on longterm follow-up. All information from the Norwegian Prescription Database will be transferred to the Norwegian Prescribed Drug Registry. The collection and use of data are controlled by a new regulation (13).

Key variables available in the NorPD are shown in table 2, the same information will be available from the Norwegian Prescribed Drug Registry. Statistical data (anonymous data) from the Norwegian Prescription Database are available for the public through a NIPH website (14) and an equivalent solution will be established for the new Norwegian Prescribed Drug Registry.

\section{DATA QUALITY AND STRENGTHS/ LIMITATIONS}

For both data sources, a major strength is the completeness of data, which minimizes both selection bias and recall bias. One limitation is that both data sources are based on sales figures and we do not have information about the actual drug intake, however data on prescription drugs dispensed in the pharmacies are "closer" to the patient than data from wholesalers. Data from wholesalers have the obvious strength in giving total

\begin{tabular}{|l|l|}
\hline Variable & Description \\
\hline 1. Aggregated sales & \\
\hline Total sales & \\
\hline Total sales per county & \\
\hline County identifiers & \\
\hline 2. Period & \\
\hline Year & Nordic Article Number ("varenummer") \\
\hline Month & $\begin{array}{l}\text { WHO-defined Anatomical Therapeutic } \\
\text { Chemical code, 1st to 5th ATC level with } \\
\text { level name }\end{array}$ \\
\hline 3. Sales of drugs & Name, size, unit, strength \\
\hline Product identifier & Defined Daily Dose \\
\hline ATC code & g, mg, IE etc \\
\hline Package information & $\begin{array}{l}\text { Narcotics, restricted drugs, prescription } \\
\text { only, Over the Counter (OTC) drugs }\end{array}$ \\
\hline DDD & $\begin{array}{l}\text { Marketing authorisation, licence sales, } \\
\text { pharmacy produced }\end{array}$ \\
\hline DDD unit & \\
\hline Prescription category & \\
\hline Regulatory status & $\begin{array}{l}\text { Calculated based on pharmacy purchase } \\
\text { price }\end{array}$ \\
\hline Number of packages sold & $\begin{array}{l}\text { Based on the invoiced pharmacy } \\
\text { purchase price with the addition of the } \\
\text { pharmacy margin including fees and VAT }\end{array}$ \\
\hline Number of DDDs sold & $\begin{array}{l}\text { Calculated pharmacy retail } \\
\text { price }\end{array}$ \\
\hline Pharmacy purchase price & \\
\hline
\end{tabular}

Table 1. Key variables included in the Norwegian Drug Wholesales Statistics.

\begin{tabular}{|l|l|}
\hline Variable & Description \\
\hline 1. Pharmacy & Identification and location \\
\hline 2. Prescriber & $\begin{array}{l}\text { Unique identifier and information; year of } \\
\text { birth, sex, profession and specialty }\end{array}$ \\
\hline 3. Patient & $\begin{array}{l}\text { Unique identifier and information; year } \\
\text { and month of birth, sex, place of } \\
\text { residence (municipality) }\end{array}$ \\
\hline 4. Dispensing information & \\
\hline Dispensing date & \\
\hline Number of packages & $\begin{array}{l}\text { For the dispensed drug according to } \\
\text { invoice from the pharmacy }\end{array}$ \\
\hline Pharmacy retail price & $\begin{array}{l}\text { Reimbursement code (national code or } \\
\text { ICPC/ICD-based code) and type of } \\
\text { reimbursement* }\end{array}$ \\
\hline Number of DDDs & \\
\hline Reimbursement & Nordic Article Number ("varenummer") \\
\hline 5. Drug dispensed & $\begin{array}{l}\text { WHO-defined Anatomical Therapeutic } \\
\text { Chemical code, 1st to 5th ATC level }\end{array}$ \\
\hline Product identifier & Name, size, unit, strength \\
\hline ATC code & Defined Daily Dose \\
\hline Package information & g, mg, IE etc \\
\hline DDD & $\begin{array}{l}\text { Narcotics, restricted drugs, prescription } \\
\text { only, Over The Counter (OTC) drugs }\end{array}$ \\
\hline DDD unit & $\begin{array}{l}\text { Marketing authorisation, licence sales, } \\
\text { pharmacy produced }\end{array}$ \\
\hline Prescription category & \\
\hline Regulatory status & \\
\hline
\end{tabular}

Table 2. Key variables included in The Norwegian Prescription Database (NorPD) *Reimbursement codes refer to ICD-10 or ICPC-2 international classification of diseases and can be used as proxies for indication for use, but with limitations.

sales figures, including drug sale without prescription and to institutions. Prescription data have the obvious strength in being registered on an individual level, providing information about number of users and information about the individual user (gender, age and geography). In NorPD the portion of dispensed drugs 
registered with valid patient identity, i.e. national identity number, has increased from $96 \%$ in 2004 to more than $99 \%$ in 2010 and onward. One limitation in the NorPD is lack of data on the indication for prescription, but reimbursement codes (ICD10/ICPC-2) on the prescription, included since 2008, are occasionally used as a proxy for diagnoses. Nevertheless, this can be resolved by linkage of drug data to other health registries with diagnoses from either primary care or hospital care settings, for instance the Norwegian Patient Registry and the Norwegian Registry for Primary Health Care.

\section{USE OF DATA IN RESEARCH - PRESENTATION AND POTENTIALS}

The two databases provide a comprehensive picture of drug sales and consumption in Norway. In 2020 the annual report from NIPH compiled data from the two data sources in one publication for the first time, "Drug consumption in Norway 2015-2019" (11), illustrating how data from these two sources complement each other. Data from the Norwegian Drug Wholesales Statistics show time trends in overall drug use in society and are well suited for generation of hypotheses. Data from the Norwegian Prescription Database provide information on an individual level and are well suited for more detailed investigation of specific research questions.

Figures 2 and 3 are examples of how data from the two sources together give a more complete picture of drug utilization. For drugs sold both with and without prescription, like paracetamol, a picture of total sale can only be obtained from the Norwegian Drug Wholesales Statistics (Fig. 2). To get a closer look at distribution on e.g. gender and age, data from the Norwegian Prescribed Drug Registry is necessary, but this information is only available for drugs on prescription and can be shown as proportion of the population (prevalence) who has received and filled at least one prescription (Fig. 3).

The relatively small population in Norway limits the feasibility of research projects with either small number of exposed patients and/or rare outcomes. However, Norway and Nordic countries have similar publicly funded health care systems where all citizens have unrestricted access to health services and with mandatory and complete drug utilization data over a long period of time. In addition, the Nordic registries of prescribed drugs have comparable design and data, making it possible to conduct studies on a Nordic level. Together, the Nordic countries represent a unique source for pharmacoepidemiological studies in a larger population $(15,16)$, altogether the prescription databases cover around 27 million inhabitants (2019).

For the NorPD and soon the Norwegian Prescribed Drug Registry, the major strength for research purposes lies in the possibility to link data to other health registries, data sources and surveys. By coupling individual level data on drug use to other individual level data, it is possible to establish associations and search for causal relationships, in addition, to study long-term

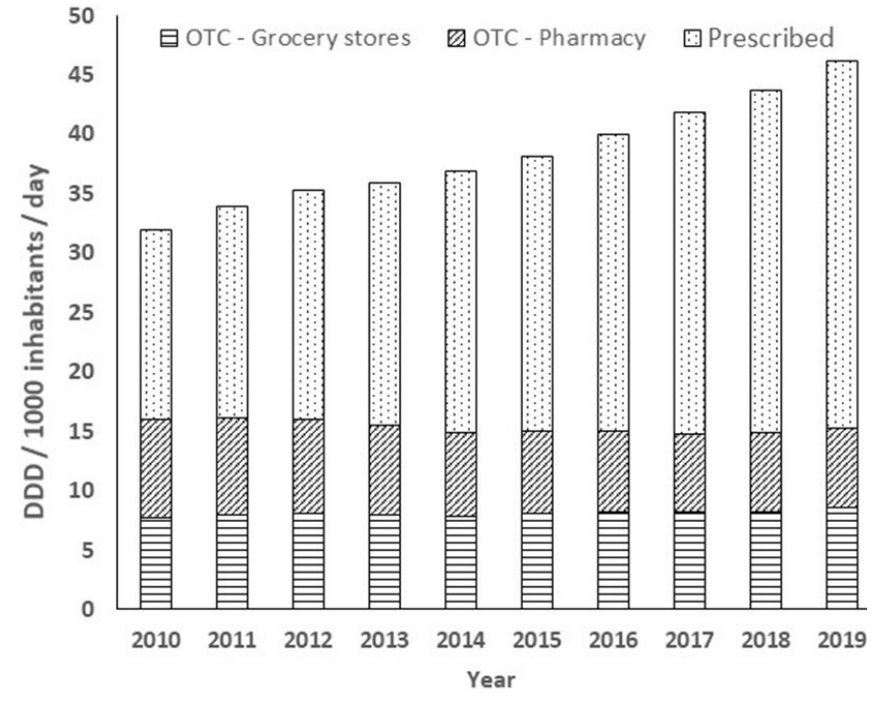

Figure 2. Sales of paracetamol in DDD/1000 inhabitants/day. OTC: over the counter. Source: Norwegian Drug Wholesales Statistics.

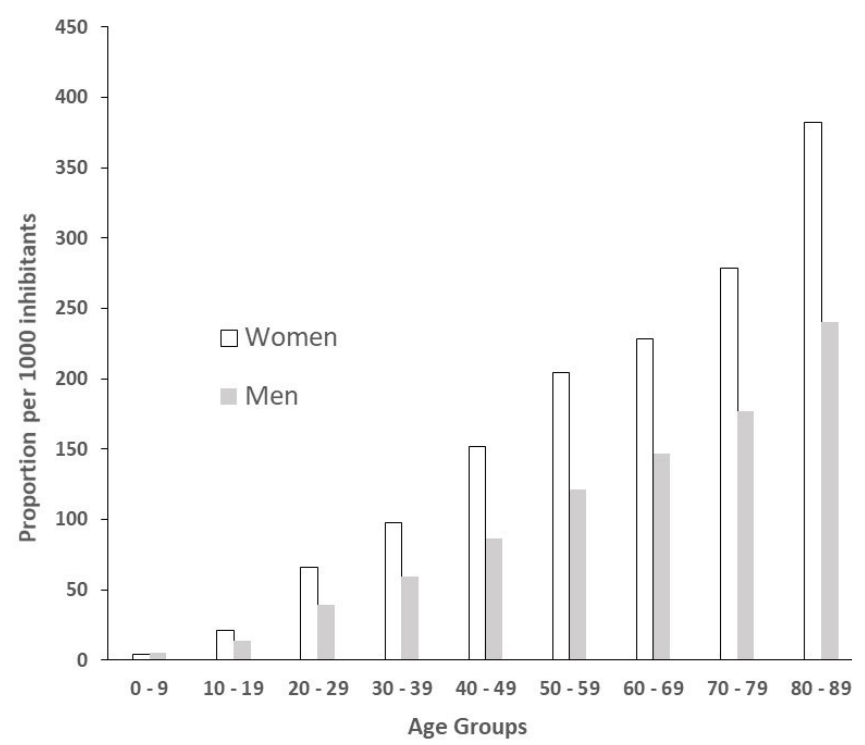

Figure 3. Dispensing of paracetamol in 2019, prevalence (proportion per 1000 inhabitants) according to age groups and gender. The oldest age group, above 90 years is omitted since individuals living in health institutions are not included in NorPD on an individual level. Source: The Norwegian Prescription Database (NorPD).

exposure or diseases with a long latent period $(15,16)$. Data can be used to investigate both use and effects of specific drugs or drug-groups in subgroups of the population in "real life", as opposed to stringent clinical trials. Subgroups of the population can be directly defined in NorPD such as gender, age-groups and geographical regions, or defined by coupling NorPD-data to other registries on health status such as pregnancy, morbidity i.e. diagnoses, health outcomes including mortality or socioeconomic status. Other important issues for use of the drug data are studies regarding compliance with governmental regulatory decisions e.g. reduction in use of antibiotics, compliance with therapeutic guidelines e.g. diabetes and cardiovascular therapy. Trends in 


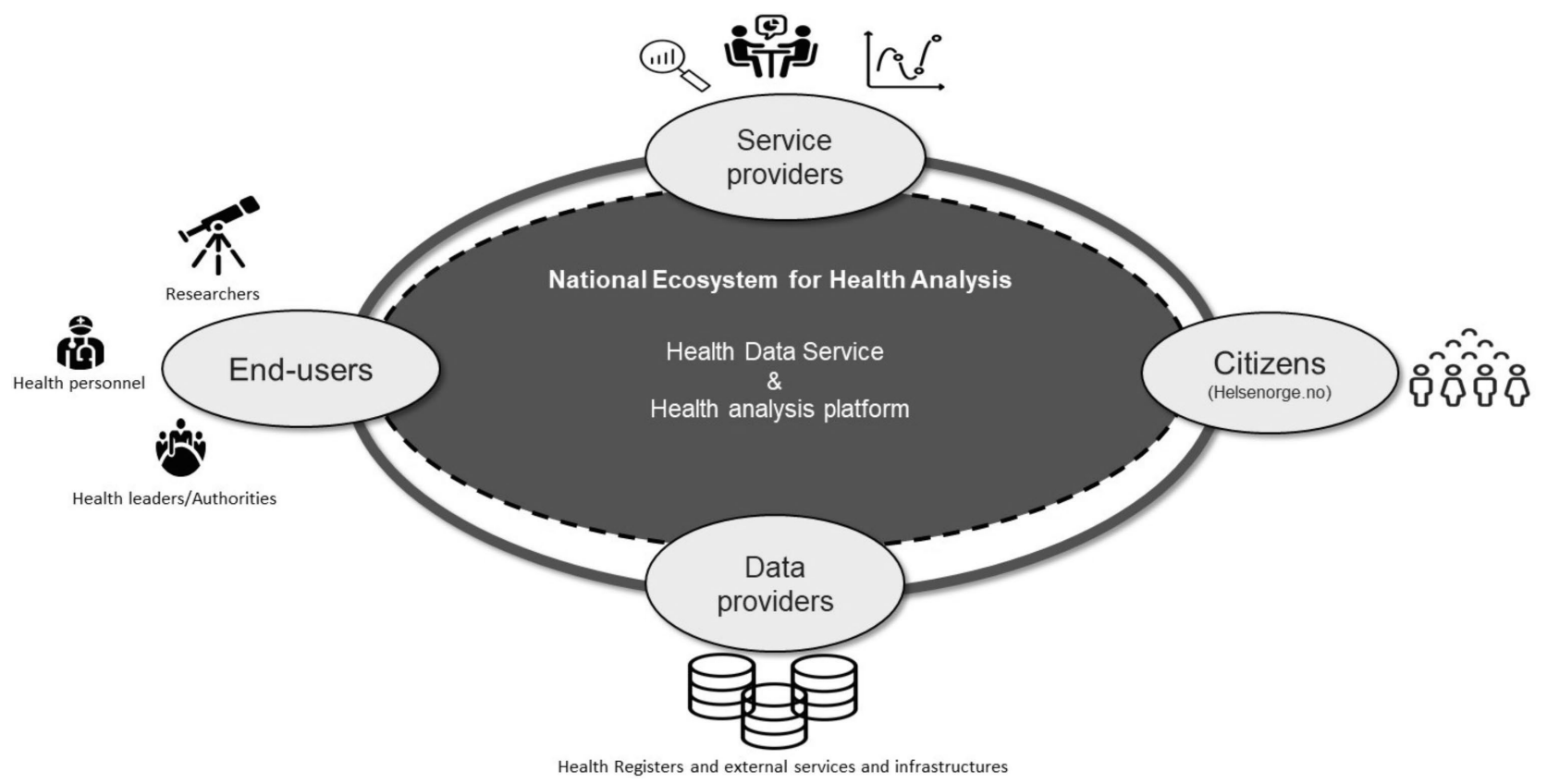

Figure 4. The Health Data Program will realize an ecosystem for health analysis - a technical platform (Health Analysis Platform) and a national "one-stop-shop" data permit authority (Health Data Service). The figure is modified with permission from the Norwegian Directorate of eHealth.

clinical practice related to new drugs, new therapeutic areas and both positive and potentially harmful drug effects (e.g. "opioid epidemic", psycholeptics in adolescents, drugs during pregnancy) can be monitored. Drug data can also be used to create quality indicators in the health care system and may serve in other contexts such as in validation of recall bias for drug use in health surveys.

\section{FUTURE IMPROVEMENTS}

The imminent (during 2021) modernization of the NorPD has been described previously. Another important issue to be solved, is obtaining individual level data on drug use among patients in health institutions such as hospitals, emergency services, short- or long-term residents of nursing homes and rehabilitation units. Inpatient data covers vulnerable patient populations and often include expensive medicines. Researchers as well as health professionals, -leaders and -authorities need these data for proper decision-making at national and local levels. One example is the project INSPIRE, which is a cooperation between the Norwegian Cancer Registry, Norwegian Cancer Association and several pharmaceutical companies. This is the first attempt to collect data on cancer drugs to the Cancer Registry directly from electronic treatment modules in hospitals in all health regions in Norway (17). Another improvement will be the introduction of a unique identifier for each health institution which will allow collection of aggregated data on drug use from each institution. Establishment of a unique identifier is in the pipeline of the Norwegian Directorate of eHealth and needs to be resolved in the future. It is a difficult task to give a sound timeframe estimate for these future improvements. If the needed finance and political drive are in place, a 5-year period should be enough to implement the abovementioned improvements.

ATC/DDD as the gold standard for drug utilisation research should be integrated and mapped to other drug identification, classifications, terminologies and e-health systems such as ISO-IDMP (identification of medicinal products) (18). Therefore, the WHO Collaborating Centre for Drug Statistics Methodology has joined the European project, upscaling the global univocal identification of medicines (19) (UNICOM).

Drug databases have also an important role in the expanding field of e-health. Flow of information, crosstalk and communication between different areas in the health care system, as well as interaction between different sectors in the society, are crucial to generate and utilize data. Several national programs are led by the Norwegian Directorate of eHealth. The "Health Data Program" is a large project that aims to gather information from important national health data sources, including the Norwegian Prescribed Drug Registry. This national ecosystem for health analysis has several goals including improved privacy and information security, more efficient registry management, better conditions for health research with easier and faster access to data for users such as researchers and medical professionals, increased innovation and business development and promotion of knowledge-based health services. The program consists of a technical part named "Health Analysis Platform" which will be the main source for analyses, presentation of and access to health data, including drug data. The organizational part is named "Health Data Service" which is the data permit 
authority (Fig. 4). Health Data Service provides the main gate and guidance for access to information about health registries and for application for data for research and innovation purposes through the web portal helsedata.no (20).

\section{CLOSING REMARKS}

The need for complete data on drug use in the society is emerging at individual, institutional, regional and national levels. Researchers need to access data fast and without unnecessary and time-demanding obstacles. This is important for operating a healthcare system by a timely manner, based on thorough decisions made on good quality data. The two nationwide databases, the Norwegian Prescription Database (soon to be Norwegian Prescribed Drug Registry) and The Norwegian Drug Wholesale Statistics, are the cornerstones of drug utilization research and pharmacoepidemiology in Norway, and will be continuously developed and adapted to the current e-health ecosystem to fulfil the needs of drug data in a modern society.

\section{REFERENCES}

1. Bergman U. The history of the Drug Utilization Research Group in Europe. Pharmacoepidemiol Drug Saf 2006; 15(2):95-8.

2. Dukes M. Drug utilization studies: methods and uses 1993. Available from: https://www.euro.who.int/_data/assets/pdf_file/0011/156782/euro_series_45.pdf.

3. Sakshaug S, Andrew M, Hjort PF, Lunde PKM, Øydvin K. Drug utilization in Norway during the 1970s increases, inequalities, innovations. Aktietrykkeriet, 1983.

4. McBride W. Thalidomide and congenital malformations. Lancet 1961;1:358.

5. Lenz W. Thalidomide and congenital abnormalities. Lancet 1962;1(45):271-2.

6. WHO Collabrating Centre for Drug Statistis Methodology. Guidelines forATC classificationand DDD assignment 2021. Available from: https://www.whocc.no/filearchive/publications/2021_guidelines_web.pdf.

7. Rønning M. Coding and classification in drug statistics - From national to global application. Norsk Epidemiologi 2001;11(1):37-40.

8. Organisation for Economic Co-operation and Development. OECD, Statistics [Available from: https://stats.oecd.org/Index.aspx?DataSetCode=HEALTH_PHMC.

9. Furu K. Establishment of the nationwide Norwegian Prescription Database (NorPD) - new opportunities for research in pharmacoepidemiology in Norway. Nor J Epidemiol. 2008(18):129-36.

10. Ministry of Health and Care Services. Regulations on wholesale activities with pharmaceuticals 2020 [Available from: https://lovdata.no/dokument/SF/forskrift/1993-12-21-1219.

11. National Institute of Public Health. Drug Consumption in Norway 2015-2019. Available from: https://www.fhi.no/contentassets/00c2c40952bb4c3da07216b656b72a7b/rapportlegemiddelstatistikk-2020.pdf.

12. Ministry of Health and Care Services. Health Register Act; Lov om helseregistre og behandling av helseopplysninger (helseregisterloven) 2020. Available from: https://lovdata.no/dokument/NL/lov/2014-06-20-43.

13. Ministry of Health and Care Services. Forskrift om innsamling og behandling av helseopplysninger i Legemiddelregisteret (LMR-forskriften) 2021. Available from: https://lovdata.no/dokument/LTI/forskrift/2021-0326-969.

14. Norwegian Institute of Public Health. The Norwegian Prescription Database. Available from: http://www.norpd.no/.

15. Furu K, Wettermark B, Andersen M, Martikainen JE, Almarsdottir AB, Sorensen HT. The Nordic countries as a cohort for pharmacoepidemiological research. Basic Clin Pharmacol Toxicol 2010;106(2):86-94.

16. Wettermark B, Zoega H, Furu K, Korhonen M, Hallas J, Norgaard M, et al. The Nordic prescription databases as a resource for pharmacoepidemiological research - a literature review. Pharmacoepidemiol Drug Saf 2013; 22(7):691-9.

17. Norwegian Cancer Registry. INSPIRE - information on drug cancer treatment 2021. Available from: https://www.kreftregisteret.no/Forskning/Prosjekter/inspire2/.

18. European Medicines Agency. Data on medicines (ISO IDMP standards). Available from: https://www.ema.europa.eu/en/human-regulatory/overview/data-medicines-iso-idmp-standards-overview.

19. The UNICOM Innovation Action. Up-scaling the global univocal identification of medicines. Available from: https://unicom-project.eu/.

20. Norwegian Directorate of eHealth. Guidance and tools to access high quality health data for research and innovation purposes. Available from: https://www.helsedata.no/. 